\title{
Lifesaving water quality solution 'ignored'
}

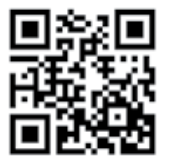

A filtration unit that can deliver cheap, safe drinking water to 200 people for 3 years, giving dysfunctional rural municipalities more than enough time to fix broken pipes and polluted water sources and/or increase their maintenance capacity, is being ignored by South Africa (SA)'s health officials.

With infants in poor rural communities at daily risk of diarrhoea and even cholera as epitomised by the 80 deaths of babies from a malfunctioning and decaying water reticulation system in the former Ukahlamba District of Barkly East in April 2008 ${ }^{[1]}$ - the potential for a repeat occurrence remains high.

A recent national report commissioned by the Department of Water and Sanitation (DWS) concludes that poor operation and maintenance of the water supply, treatment and reticulation infrastructure is resulting in 'significant losses' of water (loss of life omitted), which if corrected can reverse current water shortages. The May 2013 strategic overview by the then Department of Water Affairs (DWA) found that there was no surplus water in SA, that available water resources were at their limit, and that climate change would worsen the situation. Poorly maintained reticulation systems aside, many rural communities rely on untreated raw water from rivers, springs or boreholes, with many of these sources (particularly but not only in the Eastern Cape) contaminated as a result of lack of proper land management and 'source protection'. In a survey carried out after the Duzi Canoe Marathon in 2012, $40 \%$ of the field was found to have gone down with chronic diarrhoea. Tests showed that the levels of human faecal contamination of the Umsunduzi River were 115000 parts per $100 \mathrm{~mL}$ (the internationally accepted count being 150/100 mL). The Umgungundlovu District through which the Umsunduzi runs has the highest diarrhoea rate in the country. A DWS study, 'Support to the implementation and maintenance of reconciliation strategies for towns in the southern planning region' by one of the country's leading strategic resource planning and management consultancies, Umvoto Africa, has shown that most of the water supply problems and restrictions experienced in many towns and villages in the Eastern and Western Cape could be avoided by proper management of existing schemes. A shortage of appropriately qualified engineers correlates closely with municipalities with the

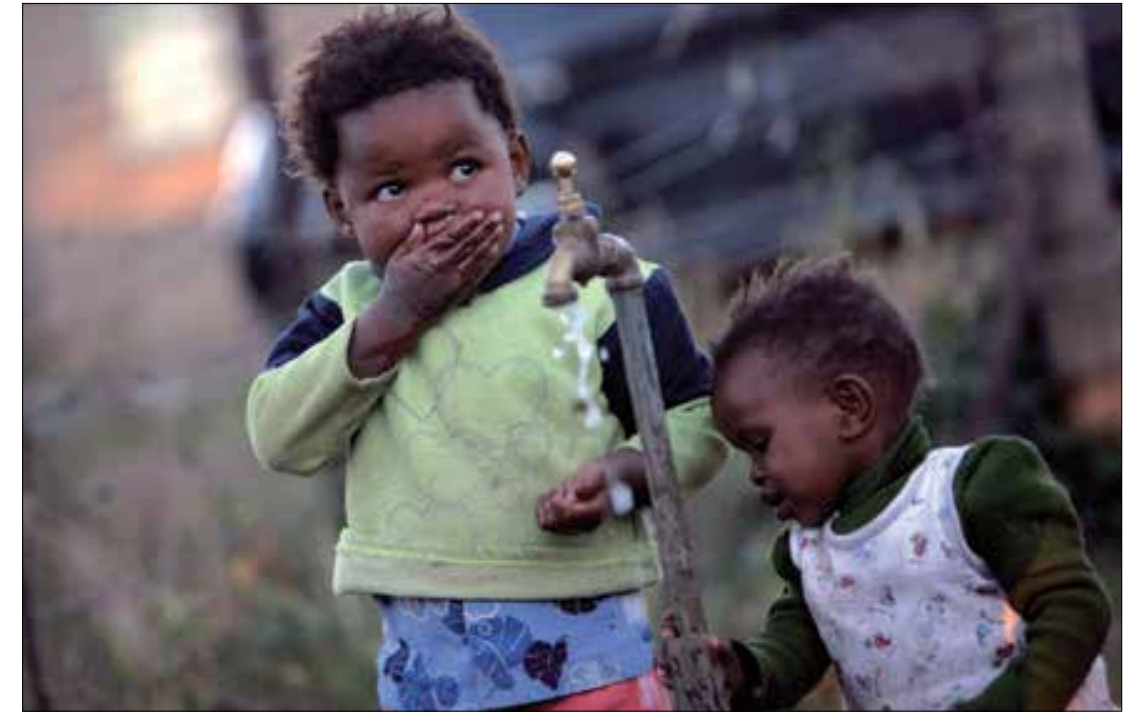

Yonele Jamta, age 4, who lost her 22-month-old brother Siviwe, and Pamela Fuma, age 2, playing at one of Barkly East's formerly deadly communal taps in 2008. Photo: Nigel Louw, Daily Dispatch.

poorest water safety and supply and sanitation records.

\section{Globally leading technology on hand}

The applicable LifeStraw technology, available for the past 9 years and winner of ten top international awards for excellence in design and technology (including Time Magazine's Invention of the Year, 2005, and Popular Science's A Water Purifier for the Masses), outperforms any similar device on the SA market, exceeding the World Health Organization's criteria of the 'highly protective' category for microbiological performance. The community model uses two 25-litre chambers, the upper of which can be filled with river, puddle, rain or even turbid surface water. A lever on the lower chamber enables expulsion of all the filtered dirty water, at least once a week. Already the prevalence of infant and child diarrhoea at one of four modest NGO-sponsored projects, a crèche in Masiphumelele township in Kommetjie, Cape Town, serving 106 small children (34 HIV/AIDS-infected), has dropped by $100 \%$. Only one of the crèche babies was still suffering from diarrhoea this March, 2 months after implementation. Lifestraws are also in use at the Ikamva Labantu Crèche in Khayelitsha (Cape Town), in Hluhluwe (northern KwaZulu-Natal) and in the Makadesh squatter community in Pretoria. The company is marketed in SA as
Aqua4Life. CEO Nico Germishuizen, who holds the southern African distribution rights for LifeStraw (manufactured by Swiss-based global health solutions company Vestergaard, which also produces the popular long-lasting insecticidal PermaNet malaria bed nets), said that he was still awaiting data on the impact of the devices in the other three areas.

\section{Kenya's success story}

In Kenya's Western Province, where Vestergaard has been operating for 6 years, family (smaller) water purifiers were provided to 877505 households in 2011 alone, with ongoing provision and back-up safe water education and training in 300 schools. The impact on providing safe water to 125000 schoolchildren (data not yet collated and interpreted) hardly needs much imagination. Germishuizen told Izindaba that a community unit costs about ZAR5 000, which works out at about $5 \mathrm{c}$ per litre over 3 years, after which the unit is replaced by the funding entity. Ironically, the introduction of the product to the local market is a spin-off of his environmental health and safety business losing mining contracts in the downscaling aftermath of the Marikana mine police killings. 'I was looking for another income stream and came across this company looking for new operators in this terrain, he says. His company donates one unit to provide a child with safe, free drinking water for a year for every unit sold, 'banks' this 'unit', and then 
distributes a community water purifier to preidentified high-risk communities, a result of Vestergaard's 'Follow the Litres' project.

\section{The cost of implementing charity projects}

Germishuizen is sitting with an excess of units in stock because, as he puts it, the appetite for community social investment in SA is on the wane. 'We know of several projects that are available, but people at the helm of charities are seeing millions spent with very little benefit to their causes.' He puts this down to the ' 80 20 syndrome', where $80 \%$ of donations go to overheads and $20 \%$ trickle down to project implementation. He's finding his work cut out to convince NGOs (and governments and local authorities) that the equation for his service is exactly the other way around, because of the efficacy and robustness of the product. His company is BEE compliant (partnering with a Department of Trade and Industry-sponsored empowerment outfit that supplies only paper soap to schools and communities and desperately needed a more product-legitimate partner). However Aqua4Life remains on 'the outer fringes' and currently relies on the private sector to 'do what we need to do.' 'From time to time we get international funding, which helps a lot,' Germishuizen said. He described his franchise and parent company as a 'profitfor-good outfit in the humanitarian channel', adding: 'Yes, at the end of the day we're a business, but we do good.' Their main partner in the fight for clean water and sanitation is Rotary International Club of Sea Point's Dr Tony Davidson, who helps identify projects and implementation strategies, with back-up by top Vestergaard executives.

Germishuizen said it was 'in the nature of things' that babies had to die before publicity was generated and action taken (remedial action after the Eastern Cape Ukahlamba tragedy took months), adding that while provinces and municipalities 'get their act together, we can supply a solution that can buy them $9-15$ years of time. Asked about competing products of similar quality in SA, he said there were none. Seemingly similar local products all worked on carbon-activated filters that 'only take out the rancid taste of chlorine or fluoride and some other stuff, but not the stuff that makes you sick. His filters, of which there are varying sizes ranging from a backpacking flask to the community unit, were SA Bureau of Standards approved. He challenged any local company to test their product against the LifeStraw units for efficacy and safety.

In a survey carried out after the Duzi Canoe Marathon in $2012,40 \%$ of the field was found to have gone down with chronic diarrhoea. Tests showed that the levels of human faecal contamination of the Umsunduzi River were 115000 parts per $100 \mathrm{~mL}$ (the internationally accepted count being 150/100 $\mathrm{mL}$ ).

The Umgungundlovu district through which the Umsunduzi runs has the highest diarrhoea rate in the country.

\section{Blue Drop success exaggerated}

The much-touted DWA Blue Drop incentivebased water quality regulation strategy ${ }^{[2]}$ was introduced in 2008 after alarming reports found $68 \%$ of municipalities unable to say whether or not they met drinking water quality standards, with supplies to $37 \%$ of households interrupted for at least one day (2003 data). ${ }^{[2]}$ While unique in the international regulatory domain, the private sector however claims that the strategy is being subject to a strong government 'spin element', with water quality actually deteriorating nationally. In 2009, 23 water supply systems obtained the Blue Drop certification (which includes compliance with water quality standards and verifying the existence of a water safety plan). In 2010, nine lost it and 24 gained it for the first time, bringing the total to 38 (less than 5\% of the 787 systems assessed). The three top performers were Johannesburg, Cape Town and the small rural town of Bitou (in the Plettenberg Bay area of the Western Cape). Eutrophication (nutrient enrichment of water, often by farm fertiliser run-off, which causes algal blooms) is cited as a 'growing concern', with about one-third of the total volume of water held in strategic storage approaching the point where it is no longer 'fit for purpose' without significant and costly management intervention. Much remains to be done to fulfil people's constitutional right to 'sufficient food and water'. An obstinate refusal to look to the private sector for what would be a costeffective medium- to long-term solution will almost certainly aggravate matters.

\section{Chris Bateman}

chrisb@hmpg.co.za

S Afr Med J 2015;105(5):333-334. DOI:10.7196/SAMJ.9684

\footnotetext{
1. Bateman C. Incompetent maintenance/inept response; 80 more E Cape babies die. S Afr Med J 2008;98(6):429-430.

2. Wikipedia. Water supply and sanitation in South Africa. en.wikipedia.org/wiki/Water_supply_and_sanitation_in South_Africa (accessed 13 April 2015).
} 